\title{
Salmonella Enteritidis reduction in layer ceca with a Bacillus probiotic
}

\author{
Paul T. Price ${ }^{1,2}$, Thomas A. Gaydos ${ }^{3}$, Roy D. Berghaus ${ }^{4}$, Virginia Baxter ${ }^{5}$, Charles L. Hofacre ${ }^{5}$ and Michael D. Sims ${ }^{6}$ \\ 1. Phileo by Lesaffre Milwaukee, Wisconsin, United States; 2. Department of Food, Nutrition, and Packaging Sciences \\ Clemson University Clemson, South Carolina, United States; 3. Gaydos Technical Services, LLC, Dallas, Texas, \\ United States; 4. Department of Population Health College of Veterinary Medicine, University of Georgia, Athens, \\ Georgia; 5. Southern Poultry Research Group, Inc., Watkinsville, Georgia; 6. Virginia Diversified Research, Harrisonburg, \\ Virginia, United States. \\ Corresponding author: Paul T. Price, e-mail p.price@phileo.lesaffre.com \\ Co-authors: TAG: gaydosdvm@gmail.com, RDB: berghaus@uga.edu, VB: jbaxter@thesprgroup.com, \\ CLH: clhofacre@thesprgroup.com, MDS: mdsims@comcast.net \\ Received: 06-11-2019, Accepted: 11-12-2019, Published online: 25-01-2020
}

doi: www.doi.org/10.14202/vetworld.2020.184-187 How to cite this article: Price PT, Gaydos TA, Berghaus RD, Baxter V, Hofacre CL, Sims MD (2020) Salmonella Enteritidis reduction in layer ceca with a Bacillus probiotic, Veterinary World, 13(1): 184-187.

\begin{abstract}
Background and Aim: Salmonella Enteritidis (SE) is a significant foodborne pathogen that can often be traced to poultry and poultry products. This study aims to evaluate the ability of three commonly used non-antimicrobial feed additives in reducing the amount of SE in the ceca of laying type pullets.
\end{abstract}

Materials and Methods: On day 0, 60 Hy-Line Brown pullets aged 9 weeks were allocated to individual cages in 15 replicate blocks of four pens. Pullets were administered a mash feed provided ad libitum without supplementation (control) or with dietary supplementation of $454 \mathrm{~g} /$ ton yeast cell wall (YCW), or $454 \mathrm{~g} /$ ton Bacillus spp. probiotic, or $1133 \mathrm{~g} /$ ton yeast culture (YC). On day 3 of the trial, all birds were orally administered $3 \times 10^{7} \mathrm{CFU}$ of a nalidixic acid-resistant SE. On day 10, 7 days after inoculation, all birds were humanely euthanized, and the ceca were aseptically removed for analysis.

Results: There was no significant difference in the prevalence of SE among treatments. The mean quantity of SE detected in the ceca expressed in $\log _{10}$ most probable number/g was 2.52 in the control, 2.49 in the YCW treatment, 1.73 in the probiotic treatment, and 1.66 in the $\mathrm{YC}$ treatment. The reduction between control and probiotic and control and $\mathrm{YC}$ was significant $(\mathrm{p}=0.021)$.

Conclusion: This study demonstrates the ability of the novel probiotic and the YC to reduce the load of SE in layer ceca.

Keywords: layers, probiotic, Salmonella Enteritidis, yeast cell wall, yeast culture.

\section{Introduction}

Salmonella is a significant cause of foodborne illness worldwide; in the United States, an estimate of 18.3 cases $/ 100,000$ population is reported [1]. The EU 20.4 cases/100,000 population are observed [2]. Salmonella Enteritidis (SE) is one of the most commonly isolated serotypes from clinical cases of salmonellosis, accounting for $14.5 \%$ of the US cases in 2012 and $39.5 \%$ of European cases in 2013 [2,3]. Approximately $29 \%$ of human salmonellosis cases can be attributed to poultry products [4]. This is not surprising as it is generally accepted that many serovars of Salmonella enterica can thrive in the gastrointestinal tract of poultry.

The poultry industry strives to reduce the risk of Salmonella in processing and production, including but not limited to processing aids, washing, biosecurity, vaccines, and a plethora of non-antimicrobial feed additives.

Copyright: Price, et al. Open Access. This article is distributed under the terms of the Creative Commons Attribution 4.0 International License (http://creativecommons.org/licenses/by/4.0/), which permits unrestricted use, distribution, and reproduction in any medium, provided you give appropriate credit to the original author(s) and the source, provide a link to the Creative Commons license, and indicate if changes were made. The Creative Commons Public Domain Dedication waiver (http://creativecommons.org/ publicdomain/zero/1.0/) applies to the data made available in this article, unless otherwise stated.
The market is filled with many different types of feed additives that are related with different modes of action aiming to improve health and performance of all agricultural species, including poultry $[5,6]$. Saccharomyces cerevisiae yeast cell wall (YCW) has been shown to improve intestinal health in Clostridium challenged broilers [7] and nutritionally challenged broilers [8]. YCW can improve economic performance and egg quality parameters when it is included in the diets of laying hens $[9,10]$ and a reduction of Salmonella Typhimurium levels [11] and SE [12] in layer ceca is observed. YCW has also been shown to reduce the levels of Salmonella Heidelberg in broilers [13]. Mannanoligosaccharide supplementation resulted in reduced SE shedding from broiler chickens [14]. Many different species and strains of probiotic bacteria have been commercialized for the poultry industry. Bacillus subtilis probiotics have been shown to improve broiler performance and intestinal microbiota [15] and improve performance in birds with necrotic enteritis [16]. Bacillus amyloliquefaciens has been shown to improve feed conversion ratio in broilers [17]. Bacillus subtilis and Bacillus licheniformis probiotics have been shown to improve performance and reduce Escherichia coli shedding in laying hens [18]. There are also data to support the reduction of Salmonella in broilers with a B. subtilis 
probiotic [19]. Data related to Salmonella reduction with Bacillus probiotics in laying hens are limited. Bacillus cereus var. toyoi reduced the prevalence of $\mathrm{SE}$ in layer ceca [20]. Another commonly used feed additive is the yeast culture (YC), it has been shown to have performance and immunomodulatory effects in broilers [21].

This study aimed to address the ability of a commercially available YCW, a novel probiotic blend, or a commercially available YC to reduce the level of SE in the ceca of laying type pullets.

\section{Materials and Methods}

\section{Ethical approval}

The US National Research Council's guidelines for the care and use of laboratory animals were followed.

\section{Animal husbandry and diets}

Sixty Hy-Line Brown pullets were obtained from a commercial pullet rearing facility at approximately 6 weeks of age. The birds were transported to the research site and raised together for 3 weeks on control mash feed. The birds were then randomly assigned to 15 replicate blocks of four pens each. The pens provided $0.14 \mathrm{~m}^{2} / \mathrm{bird}$. The birds had access to mash feed and water ad libitum for the duration of the trial. A basal diet was formulated to meet or exceed the current United States National Research Council recommendations for the age of bird. The basal diet was divided into four equal portions. All birds were individually weighed at the start of the trial (day 0) and at trial termination (day 10). The treatments were as follows: Without supplementation (control) and with dietary supplementation of a commercially available YCW at $454 \mathrm{~g} /$ ton, or a commercially available probiotic containing $B$. amyloliquefaciens, $B$. licheniformis, and Bacillus pumilus (probiotic) at $454 \mathrm{~g} / \mathrm{ton}$, or a commercially available YC at $1133 \mathrm{~g} /$ ton. The pullets were fed with the experimental diets for a 3 -day acclimation period. The inclusion rates were selected from the product labels.

\section{Inoculation and sample collection}

After the acclimation, the birds were orally gavaged with $3 \times 10^{7} \mathrm{CFU}$ of a nalidixic acid-resistant SE. On 7 days post-challenge, all pullets were humanely euthanized. Ceca were aseptically removed and placed into sterile plastic bags for Salmonella isolation. Samples were packed on ice and shipped overnight to the laboratory for Salmonella analysis.

\section{Microbiology}

For isolation and identification of Salmonella, individual cecal samples were weighed, and $50 \mathrm{ml}$ of Tetrathionate Broth was added to each ceca sample. Samples were mixed using a stomacher for $1 \mathrm{~min}$ and incubated for $24 \mathrm{~h}$ at $42^{\circ} \mathrm{C}$. A loop full of incubated media was struck to xylose lysine tergitol-4 (XLT-4) plates containing $25 \mu \mathrm{g}$ of nalidixic acid $/ \mathrm{mL}$ to facilitate the selection of the antimicrobial-resistant challenge organisms, and plates incubated for $24 \mathrm{~h}$ at $37^{\circ} \mathrm{C}$. Suspect Salmonella colonies were confirmed and serogrouped using poly-O Salmonella-specific antiserum. Salmonella were enumerated using a modification of the most probable number (MPN) method [22]. A $1 \mathrm{~mL}$ sample of pre-incubation 1:10 Tetrathionate Broth from each sample was transferred to three adjacent wells in the first row of a 96-well $2 \mathrm{~mL}$ deep block. A $0.1 \mathrm{~mL}$ aliquot was transferred to $0.9 \mathrm{~mL}$ of Tetrathionate Broth in the second row. This process was repeated for remaining rows producing 5, 10-fold dilutions. Blocks were incubated for $24 \mathrm{~h}$ at $42^{\circ} \mathrm{C}$. One microliter of each well was transferred onto XLT-4 agar containing nalidixic acid with a sterile multichannel pipette and plates were incubated for $24 \mathrm{~h}$ at $37^{\circ} \mathrm{C}$. The final dilution of each sample was recorded, and MPN calculations were performed as previously described. Suspect Salmonella isolates were confirmed by poly-O antisera.

\section{Statistical analysis}

The lower quantitative limit of the MPN was $0.3 \times 10^{\circ} \mathrm{MPN} / \mathrm{mL}$, and the upper quantitative limit was $1.1 \times 10^{5} \mathrm{MPN} / \mathrm{mL}$. Salmonella prevalences in ceca samples were compared among the treatment groups using Fisher's exact test. Salmonella MPNs in culture-positive ceca were compared among groups using the Kruskal-Wallis test, with post hoc pairwise comparisons performed using Dunn's procedure. For the comparison of Salmonella MPNs, samples with a negative culture result by the MPN method, but a positive result by primary or secondary enrichment was arbitrarily assigned an MPN equal to one-half of the minimum detection limit of the MPN assay. MPNs were $\log$ transformed before statistical analysis. All statistical testing assumed a two-sided alternative hypothesis and $\mathrm{p}<0.05$ was considered statistically significant. Analyses were performed using commercially available statistical software (Stata version 15.1, StataCorp LLC, College Station, TX, USA).

\section{Results and Discussion}

There were neither significant differences in body weight nor weight gain among treatments. This finding was expected due to the short duration of the trial. Salmonella prevalences in ceca are presented in Table-1. The untreated control and YC groups had $14 / 15$ birds or $93.3 \%$ test positive for Salmonella. The YCW and probiotic treatment groups had $15 / 15$ or $100 \%$ of the ceca test positive for Salmonella. There was no significant difference among treatments with respect to Salmonella prevalence in ceca samples $(\mathrm{p}=1.00)$. All Salmonella isolates obtained from ceca were identified as belonging to serogroup $\mathrm{D}$, which was consistent with the SE challenge strain. Salmonella MPNs for culture-positive ceca samples are shown in Table-2. There was a significant difference among treatments $(\mathrm{p}=0.021)$. The untreated control group and the YCW group were not significantly different from each other, but both had a higher median Salmonella 
Table-1: Salmonella prevalence (\%) in ceca samples by treatment group. Fifteen individually housed birds were sampled from each treatment group at 7 days post-challenge.

\begin{tabular}{lccc}
\hline Treatment & $\begin{array}{c}\text { Number } \\
\text { of } \\
\text { samples }\end{array}$ & $\begin{array}{c}\text { Number } \\
\text { of positive } \\
(\mathbf{\%})\end{array}$ & ${ }^{+} \mathbf{p}$-value \\
\hline $1-$ Control & 15 & $14(93.3)^{\mathrm{a}}$ & 1.00 \\
$2-$ YCW $(454 \mathrm{~g} / \mathrm{t})$ & 15 & $15(100)^{\mathrm{a}}$ & \\
3 - Probiotic $(454 \mathrm{~g} / \mathrm{t})$ & 15 & $15(100)^{\mathrm{a}}$ & \\
$4-$ YC $(1133 \mathrm{~g} / \mathrm{t})$ & 15 & $14(93.3)^{\mathrm{a}}$ & \\
Total & 60 & $58(96.7)$ & \\
\hline
\end{tabular}

${ }^{\dagger}$ Fisher's exact test. aPercentages with a superscript in common do not differ with a level of significance of 5\% when using the Bonferroni multiple comparison procedure

Table-2: Summary of Salmonella $\log _{10}$ most probable number/g in culture-positive ceca samples by treatment. Fifteen individually housed birds were sampled from each treatment group at 7 days post-challenge.

\begin{tabular}{lllll}
\hline Treatment & $\mathbf{n}$ & $\begin{array}{c}\text { Mean } \\
\text { (SD) }\end{array}$ & Median & ${ }^{\dagger} \mathbf{p}$-value \\
\hline 1 - Control & 14 & $2.52(0.98)$ & $2.36^{\mathrm{a}}$ & 0.021 \\
2 - YCW $(454 \mathrm{~g} / \mathrm{t})$ & 15 & $2.49(0.66)$ & $2.44^{\mathrm{a}}$ & \\
3 - Probiotic (454 g/t) & 15 & $1.73(0.85)$ & $1.43^{\mathrm{b}}$ & \\
$4-$ YC $(1133 \mathrm{~g} / \mathrm{t})$ & 14 & $1.66(1.23)$ & $1.37^{\mathrm{b}}$ & \\
\hline${ }^{\dagger}$ Kruskal-Wallis test. a,b Medians with a superscript in \\
common do not differ with a level of significance of 5\% \\
\multicolumn{4}{l}{ when using Dunn's multiple comparison procedure }
\end{tabular}

$\log _{10}$ MPN/g than the probiotic and YC groups. The values for probiotic and $\mathrm{YC}$ groups were not significantly different from each other. The probiotic group had a mean reduction of $0.79 \log _{10}$ MPN/g compared to the control; the $\mathrm{YC}$ had a similar mean reduction of $0.86 \log _{10} \mathrm{MPN} / \mathrm{g}$. The YC group had numerically the lowest MPN/g of Salmonella in the cecal contents, but the largest standard deviation compared to the other groups. Although the previous work has shown the ability of YCW $[11,13]$ and mannooligosaccharide supplementation [14] to reduce Salmonella numbers or prevalence in chicken intestines, these results were not confirmed in this experiment. Variable results in reducing Salmonella are also reported for YCW treatments [23]. The probiotic group had a similar reduction in Salmonella numbers to the $\mathrm{YC}$ and a smaller standard deviation. YC has reduced the level of S. Typhimurium using an in vitro model [24]. This study also showed an increase in acetate and butyrate production in the ceca fermentation. Organic acids can reduce Salmonella in poultry [25]. The reduction of SE in poultry by $\mathrm{YC}$ has been discussed in popular press, but the authors found no peer-reviewed studies to support this. A study by Kiros et al. showed no reduction of Salmonella Heidelberg in broiler ceca by YC [13]. The reduction of Salmonella in poultry by Bacillus species in poultry has been demonstrated previously $[20,26]$. Probiotics can positively impact the intestinal microflora of chickens [27]. B. amyloliquefaciens has reduced the level of $E$. coli in broiler chicken digesta [28]. The reduction of SE could be attributed to a modification of the microflora in the ceca.

\section{Conclusion}

The uniform reduction of SE in the ceca in the probiotic treatment group demonstrates that this product is a possible pre-harvest food safety intervention by reducing a load of Salmonella in the ceca, thus reducing the possible contamination to the environment and consequently the eggshell. The YC treatment also reduced the average Salmonella load in the ceca. Both YC and probiotic should be further investigated to better understand their impacts on Salmonella in poultry.

\section{Authors' Contributions}

PTP, TAG, MDS, and CLH planned and designed the study. MDS, CLH, and VB collected and analyzed data. PTP, TAG, and RDB analyzed data and contributed to the manuscript. All authors read and approved the final manuscript.

\section{Acknowledgments}

This trial was funded by Phileo by Lesaffre, 7475 W, Main St. Milwaukee, WI 53214 USA.

\section{Competing Interests}

PTP is an employee of Phileo by Lesaffre and TAG consultants for Phileo by Lesaffre. MDS, CLH, $\mathrm{RDB}$, and VB declare that they have no competing interests.

\section{Publisher's Note}

Veterinary world remains neutral with regard to jurisdictional claims in published institutional affiliation.

\section{References}

1. Tack, D.M., Marder, E.P., Griffin, P.M., Cieslak, P.R., Dunn, J., Hurd, S., Scallan, E., Lathrop, S., Muse, A., Ryan, P., Smith, K., Tobin-D’Angelo, M., Vugia, D.J., Holt, K.G., Wolpert, B.J., Tauxe, R. and Geissler, A.L. (2019) Preliminary incidence and trends of infections with pathogens transmitted commonly through food foodborne diseases active surveillance network, 10 U.S. Sites, 20152018. Morb. Mortal. Wkly. Rep., 68(16): 369-373.

2. European Food Safety Authority. (2015) The European Union summary report on trends and sources of zoonoses, zoonotic agents and food-borne outbreaks in 2013. EFSA J., 13(1): 165 .

3. Centers for Disease Control and Prevention. (2014) National Enteric Disease Surveillance: Salmonella Annual Report, 2012. Centers for Disease Control and Prevention, Atlanta. Available from: https://www.cdc.gov/ncezid/dfwed/pdfs/ salmonella-annual-report-2012-508c.pdf. Last accessed on 01-12-2019.

4. Braden, C.R. (2006) Salmonella enterica serotype Enteritidis and eggs: A national epidemic in the United States. Clin. Infect. Dis., 43(4): 512-517.

5. Applegate, T.J., Klose, V., Steiner, T., Ganner, A. and Schatzmayr, G. (2010) Probiotics and phytogenics for poultry: Myth or reality? J. Appl. Poult. Res., 19(2): 194-210.

6. Hume, M.E. (2011) Historic perspective: Prebiotics, probiotics, and other alternatives to antibiotics. Poult. Sci., 
90(11): 2663-2669.

7. Fowler, J., Kakani, R., Haq, A., Byrd, J.A. and Bailey, C.A. (2015) Growth promoting effects of prebiotic yeast cell wall products in starter broilers under immune stress and Clostridium perfringens challenge. J. Appl. Poult. Res., 24(1): 66-72.

8. Fowler, J., Hashim, M., Haq, A. and Bailey, C.A. (2015) Yeast cell wall and live yeast products and their combination in broiler diets formulated with weekly ingredient variations. J. Anim. Physiol. Anim. Nutr., 99(5): 932-937.

9. Koiyama, N.T.G., Utimi, N.B.P., Santos, B.R.L., Bonato, M.A., Barbalho, R., Gameiro, A.H., Araújo, C.S.S. and Araújo, L.F. (2018) Effect of yeast cell wall supplementation in laying hen feed on economic viability, egg production, and egg quality. J. Appl. Poult. Res., 27(1): 116-123.

10. Hashim, M., Fowler, J., Haq, A. and Bailey, C.A. (2013) Effects of yeast cell wall on early production laying hen performance. J. Appl. Poult. Res., 22(4): 792-797.

11. Price, P.T., Gaydos, T., Padgett, J.C., Gardner, K. and Bailey, C. (2019) Salmonella colonization of production hens fed a parietal yeast fraction with high levels of mannan and beta-glucan. Int. J. Poult. Sci., 18(9): 410-415.

12. Hofacre, C.L., Berghaus, R.D., Jalukar, S., Mathis, G.F. and Smith, J.A. (2018) Effect of a yeast cell wall preparation on cecal and ovarian colonization with Salmonella Enteritidis in commercial layers. J. Appl. Poult. Res., 27(4): 453-460.

13. Kiros, T.G., Gaydos, T., Corley, J., Raspoet, R., Berghaus, R. and Hofacre, C. (2019) Effect Saccharomyces cerevisiae yeast products in reducing direct colonization and horizontal transmission of Salmonella Heidelberg in broilers. $J$. Appl. Poult. Res., 8(1): 23-30.

14. Lourenço, M.C., Kuritza, L.N., Hayashi, R.M., Miglino, L.B., Durau, J.F., Pickler, L. and Santin, E. (2015) Effect of a mannanoligosaccharide-supplemented diet on intestinal mucosa $\mathrm{T}$ lymphocyte populations in chickens challenged with Salmonella Enteritidis. J. Appl. Poult. Res., 24(1): 15-22.

15. Fritts, C.A., Kersey, J.H., Motl, M.A., Kroger, E.C., Yan, F., Si, J., Jiang, Q., Campos, M.M., Waldroup, A.L. and Waldroup, P.W. (2000) Bacillus subtilis C-3102 (Calsporin) improves live performance and microbiological status of broiler chickens. J. Appl. Poult. Res., 9(2): 149-155.

16. Tactacan, G.B., Schmidt, J.K., Miille, M.J. and Jimenez, D.R. (2013) A Bacillus subtilis (QST 713) spore-based probiotic for necrotic enteritis control in broiler chickens. J. Appl. Poult. Res., 22(4): 825-831.

17. Flores, C.A., Duong, T., Askelson, T.E., Dersjant-Li, Y., Gibbs, K., Awati, A. and Lee, J.T. (2019) Effects of direct fed-microorganisms and enzyme blend co-administration on growth performance in broilers fed diets with or without antibiotics. J. Appl. Poult. Res., 28(4): 1181-1188.

18. Upadhaya, S.D., Rudeaux, F. and Kim, I.H. (2019) Efficacy of dietary Bacillus subtilis and Bacillus licheniformis supplementation continuously in pullet and lay period on egg production, excreta microflora, and egg quality of hyline-brown birds. Poult. Sci., 98(10): 4722-4728.

19. Knap, I., Kehlet, A.B., Bennedsen, M., Mathis, G.F., Hofacre, C.L., Lumpkins, B.S., Jensen, M.M., Raun, M. and Lay, A. (2011) Bacillus subtilis (DSM17299) significantly reduces Salmonella in broilers. Poult. Sci., 90(8): 1690-1694.

20. Vilà, B., Fontgibell, A., Badiola, I., Esteve-Garcia, E., Jiménez, G., Castillo, M. and Brufau, J. (2009) Reduction of Salmonella enterica var. Enteritidis colonization and invasion by Bacillus cereus var. toyoi inclusion in poultry feeds. Poult. Sci., 88(5): 975-979.

21. Gao, J., Zhang, H.J., Yu, S.H., Wu, S.G., Yoon, I., Quigley, J., Gao, Y.P. and Qi, G.H. (2008) Effects of yeast culture in broiler diets on performance and immunomodulatory functions. Poult. Sci., 87(7): 1377-1384.

22. Berghaus, R.D., Thayer, S.G., Law, B.F., Mild, R.M., Hofacre, C.L. and Singer R. (2013) Enumeration of Salmonella and Campylobacter spp. In environmental farm samples and processing plant carcass rinses from commercial broiler chicken flocks. Appl. Environ. Microbiol., 79(13): 4106-4114.

23. Cox, C.M., Stuard, L.H., Kim, S., McElroy, A.P., Bedford, M.R. and Dalloul, R.A. (2010) Performance and immune responses to dietary $\beta$-glucan in broiler chicks. Poult. Sci., 89(9): 1924-1933.

24. Rubinelli, P., Roto, S., Kim, S.A., Park, S.H., Pavlidis, H.O., McIntyre, D. and Ricke, S.C. (2016) Reduction of Salmonella Typhimurium by fermentation metabolites of diamond $\mathrm{V}$ original XPC in an in vitro anaerobic mixed chicken cecal culture. Front. Vet. Sci., 3: 83.

25. Van Immerseel, F., Russell, J.B., Flythe, M.D., Gantois, I., Timbermont, L., Pasmans, F., Haesebrouck, F. and Ducatelle, R. (2006) The use of organic acids to combat Salmonella in poultry: A mechanistic explanation of the efficacy. Avian Pathol., 35(3): 182-188.

26. Menconi, A., Morgan, M.J., Pumford, N.R., Hargis, B.M. and Tellez, G. (2013) Physiological properties and Salmonella growth inhibition of probiotic Bacillus strains isolated from environmental and poultry sources. Int. J. Bacteriol., 2013(958408): 8.

27. Mountzouris, K.C., Tsitrsikos, P., Palamidi, I., Arvaniti, A., Mohnl, M., Schatzmayr, G. and Fegeros, K. (2010) Effects of probiotic inclusion levels in broiler nutrition on growth performance, nutrient digestibility, plasma immunoglobulins, and cecal microflora composition. Poult. Sci., 89(1): 58-67.

28. Lei, X.J., Ru, Y.J. and Zhang, H.F. (2014) Effect of Bacillus amyloliquefaciens based direct-fed microbials and antibiotic on performance, nutrient digestibility, cecal microflora, and intestinal morphology in broiler chickens. J. Appl. Poult. Res., 23(3): 486-493. 